\title{
THERMOELECTRIC MEASUREMENT OF CRITICAL RANGES OF PURE IRON
}

\author{
By George K. Burgess, Physicist, and H. Scott, Aid
}

\section{INTRODUCTION}

There have been a number of thermoelectric observations made over the critical ranges of iron, $A_{2}$ and $A_{3}$, using an iron wire as one element of a thermocouple and usually a platinum or copper wire as the other. ${ }^{1}$ These observations possess the disadvantage of giving the total electromotive force developed between the cold junction kept at ordinary temperatures and the hot junction immersed in the heated region of a furnace; there may thus be ambiguity or superposition of thermoelectric effects along the iron wire. Messrs. Boudouard and Le Chatelier endeavored to overcome this difficulty, in the case of certain steels, ${ }^{2}$ by using short bars to the ends of which platinum wires were attached, but were unable to get very satisfactory observations due to temperature irregularities, nor did they work with pure iron. Dr. Benedicks has recently devised a method ${ }^{3}$ which, as described, has the disadvantages above noted of ambiguity, and in addition seems to require for the detection of a transformation point that it exist at different temperatures on heating and on cooling.

It has been demonstrated, however, that the thermal effect for the transformation $\mathrm{A}_{2}$ occurs at the identical temperature $768^{\circ} \mathrm{C}$ on heating and cooling, ${ }^{4}$ and the same might be expected to be true for the thermoelectric effect. Benedicks was unable to detect any thermoelectric effect at $A_{2}$.

1 Dewar and Flemming, Phil. Mag., IV,40, p. 95, I895; Harrison, Phil. Mag., V, 3, p. '177, 1902; Broniewski, C. R., 156, pp. 699, 1983, I913.

2 Boudouard, Rev. de Métallurgie, 1, p. 80, 1904; L,e Chatelier, ibid, C. R., 102, p. 134.

${ }^{3}$ Benedicks, C. R., 162, p. 297, 1916. J1. Iron and Steel Institute, May, 1916.

- Burgess and Crowe, this Bulletin, 10: p. 315: 1914. 


\section{METHOD}

With the object of furnishing a more exact experimental basis on which to construct an adequate theory of the iron transformations, it seemed desirable to investigate the thermoelectric phenomena of pure iron more accurately than has hitherto been done. In the following experiments we have used a modification of the method of Le Chatelier giving the thermoelectric power directly, but have succeeded in eliminating the uncertainties of temperature control and distribution, have carried out the experiments in vacuo, and have used iron of exceptional purity. The observations extend over the range $0^{\circ}$ to $1000^{\circ} \mathrm{C}$ and the thermoelectric characteristics of the transformations $\mathrm{A}_{2}$ and $\mathrm{A}_{3}$ have been determined with considerable accuracy. It has been found possible to measure the thermoelectric power $(d E / d t)$ of iron against platinum for intervals of $2^{\circ}$ up to a temperature of $1000^{\circ} \mathrm{C}$, from observations in which the fall of temperature along the iron remained quite constant and was usually less than $10^{\circ} \mathrm{C}$.

\section{MATERIALS}

The iron used in these experiments was from an electrolytic deposit which had been subsequently melted in vacuo and was of an exceptionally high degree of purity, $99.968 \mathrm{Fe}$, being from sample $\mathrm{F}_{4}$ of Scientific Paper No. 213. Its analysis, in per cent, gave $C=0.009, S=0.009, P=0.001, S i=0.006, M n=0.001, C u=$ 0.006 . This was drawn through sapphire dies into wire of 0.05 $\mathrm{cm}$ diameter. The platinum of the thermocouples, and also against which the thermoelectric power of iron was determined, was from Johnson and Matthey. The thermoelectric force developed by this platinum against the purest samples of normal Heraeus thermocouple platinum was determined at $1100^{\circ} \mathrm{C} .{ }^{5}$ The difference in thermoelectric power was less than o.I microvolt, except for one series with a contaminated platinum couple.

\section{THE APPARATUS}

The apparatus is essentially the same as that used for the thermal study of the critical ranges of iron described in detail in Scientific Paper No. 213 of this Bureau. Its principal characteristics are a double-walled electric resistance furnace of $60 \mathrm{~cm}$ length in which a vacuum is maintained; an automatically controlled alternating-current supply for heating and cooling the furnace uniformly at any desired rate; a drum chrono- 
graph for recording times of observation to O.I second; a potentiometer reading to 0.1 microvolt; two galvanometers and a suitable commutator, by means of which temperatures and temperature differences may be measured to o.or ${ }^{\circ} \mathrm{C}$ and emf's of the ironplatinum couple to 0.07 microvolt.

The arrangement of the iron sample in the furnace is shown in Fig. $\mathrm{x}$. A length of iron wire 5 to $7 \mathrm{~cm}$ is inserted, either by electric welding or with the oxy-gas flame, between the junctions of two Le Chatelier thermocouples within an outglazed porcelain tube which has a small opening communicating with the vacuum space of the furnace. The iron wire is displaced slightly from the

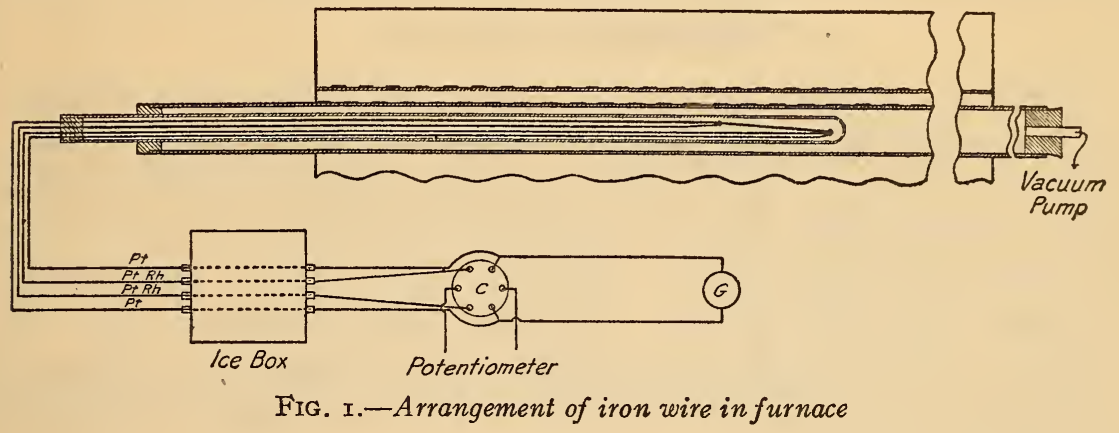

hottest region within the furnace so that a small temperature difference will always exist between the two ends of the wire; and care is taken that one end-and not an intermediate region of the wire-is its hottest part.

\section{OBSERVATIONAL METHOD}

With two observers, simultaneous observations were taken at $2^{\circ}$ intervals of $(\mathrm{I})$ the temperature of one end of the iron wire by means of a thermocouple and potentiometer (see Fig. I), and (2) the deflection of a galvanometer $(G)$ connected across the platinum wires having the iron in the circuit; every $10^{\circ}$ the temperature of the other end of the iron wire was taken with the second thermocouple. The instant of each observation was recorded on the chronograph. The true emf's of the iron-platinum couple caused by the temperature drop along the iron wire were then calculated (from 2), correction being made for the quality of platinum (negligible, except for one series) and resistance of circuit and galvanometer. This emf divided by the corresponding difference in temperature - that is, between the two ends of the iron wire $\left(2^{\circ}\right.$ to $\left.13^{\circ}\right)$-was taken as the true thermoelectric power of the iron-platinum couple at the temperature of the hot end of the iron 
wire. A few observations were also taken around $0^{\circ} \mathrm{C}$ and $100^{\circ} \mathrm{C}$ by the usual method of using an iron-platinum thermocouple having wires passing from the region of variable temperature to a constant temperature, ice or steam.

The thermocouples were carefully intercompared and calibrated several times during the experiments and several calibrations were taken of the galvanometer $(G)$ and scale giving emf's across the iron-platinum couple. Two sets of thermocouples were used, and four lengths of iron wire, all of the latter from the same analyzed sample. The rate of heating or cooling was usually of the same order of magnitude and was about $0 . x^{\circ}$ per second.

\section{EXPERIMENTAL RESULTS}

These are given in Fig. 2. For the dotted curves, the ordinates are proportional to the observed values of galvanometer deflections ( $G$ of Fig. I), which again are approximately proportional to the thermoelectric power of the iron-platinum couple. The abscissæ are temperatures. Each dot represents an observation on the respective heating or cooling curve marked "up" or "down." The dashed curves represent the differences in temperature between the two ends of the iron wire for the adjacent heating or cooling curve.

It is seen that, for the several series, $A_{3}$ is indicated by a marked discontinuity in thermoelectric power, as already noted by Benedicks and others for the emf-temperature curve. As would be expected from the thermal ${ }^{4}$ and electrical ${ }^{6}$ observations, $\mathrm{Ac}_{3}$ always occurs at a somewhat higher temperature than $\mathrm{Ar}_{3}$.

The $\mathrm{A}_{2}$ transformation manifests itself, in all cases, by an abrupt change in direction of the curve representing thermoelectric power against temperature. As shown, this is slightly above $768^{\circ} \mathrm{C}$, the maximum of the thermal transformation. - The actual location of the break in the thermoelectric curve appears to be related to the length of iron wire and the temperature distribution. The thermal transformation, absorption or evolution of heat, is also sharply marked on the curves as a protuberence or dent at exactly $768^{\circ} \mathrm{C}$. The fact that this thermal phenomenon is always recorded, even at the junction of wires only $0.05 \mathrm{~cm}$ in diameter, is further evidence of the sensitiveness of the method of measurement and of the persistence of $A_{2}$ to assert itself when given an opportunity.

The lower portions of the curves below $400^{\circ} \mathrm{C}$ are less satisfactory than at higher temperatures and for several reasons. There is 


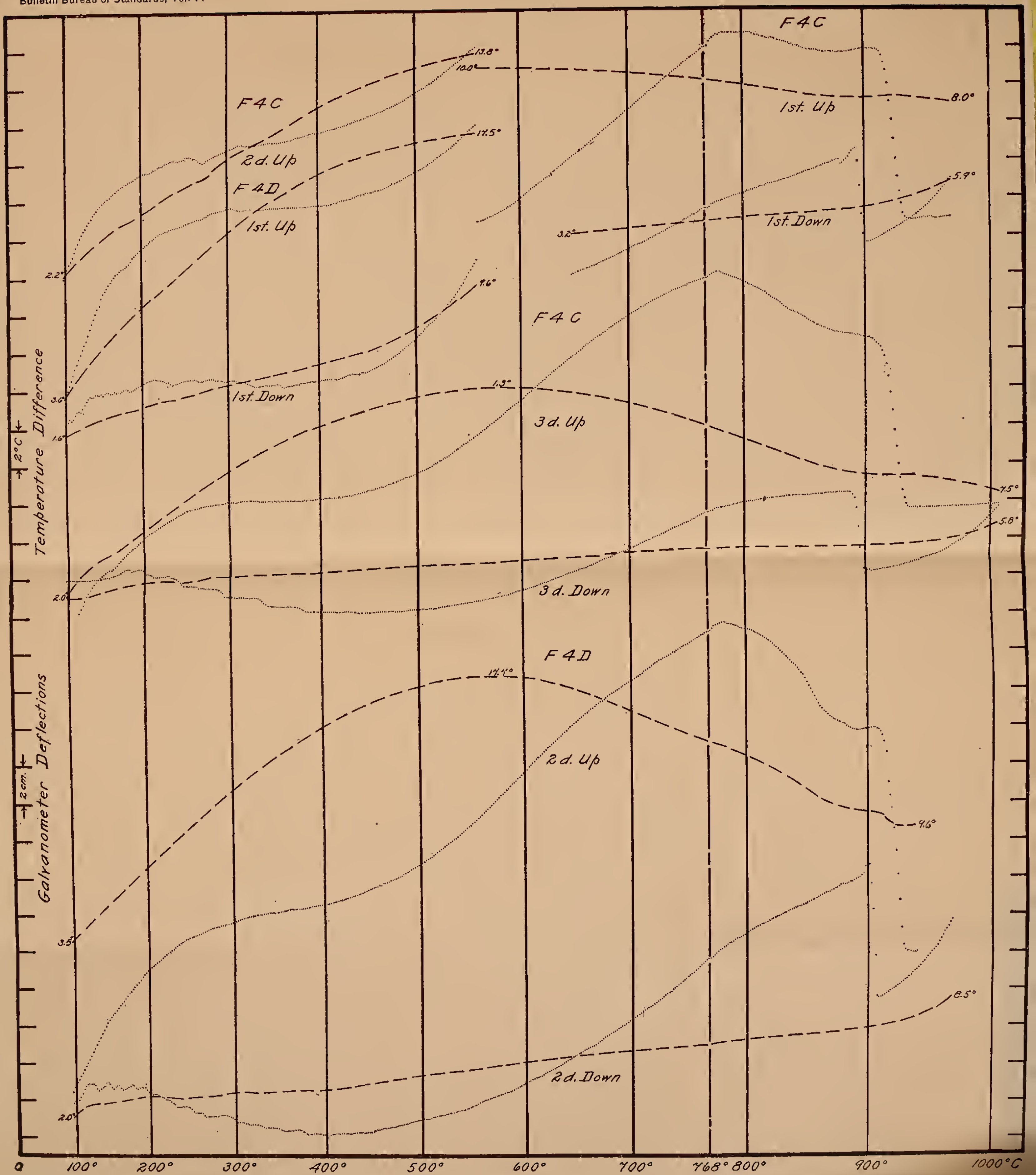

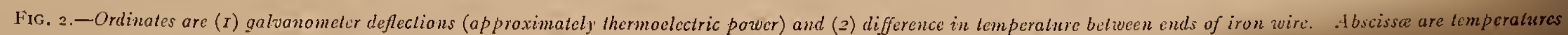


greater difficulty in obtaining uniformity of temperature distribution, greater sensitiveness to drafts, and at times there were galvanometer and pump troubles; also the heating currents below $400^{\circ} \mathrm{C}$, which protect thermally the sample, were almost if not quite zero.

It will be noted that for all the curves, the $\mathrm{A}_{1}$ transformation at about $700^{\circ} \mathrm{C}$, due to the presence of carbon, is absent. For iron containing as little as $0 . I$ per cent carbon, this $A_{1}$ point is, however, very marked, and was obtained accidentally by us when oil from the vacuum pump got into a sample of pure iron. There appears to be no permanent change in direction of the thermoelectric power curve at $A_{1}$, but this transformation produces a jagged swinging back and forth during its progress. We expect to be able to publish shortly an account of the thermoelectric properties of carbon steels.

In Table $I$ and Fig. 3 are shown the true thermoelectric power $(d E / d t)$ versus temperature between $0^{\circ}$ and $1000^{\circ} \mathrm{C}$ of the ironplatinum couple, being the most probable values computed from all the series of observations shown in Fig. 2, after all corrections are applied. The Peltier effect, $T d E / d t$ or the product of the absolute temperature and thermoelectric power is also shown. There is also given the values of $d^{2} E / d t^{2}$, which is proportional to the Thomson effect for iron.

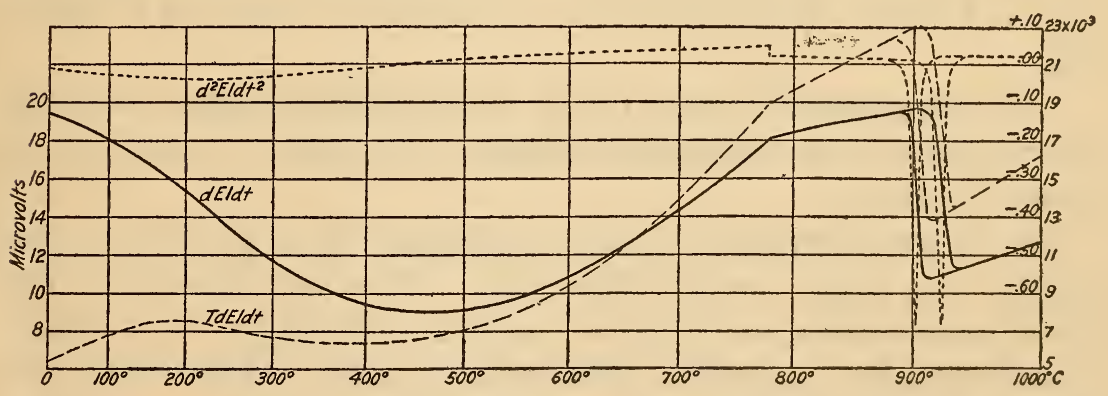

FIG. 3.-Thermoelectric power, Peltier effect and Thompson effect for iron-platinum 
TABLE 1

Thermoelectric Power of Iron Against Platinum

\begin{tabular}{|c|c|c|c|c|c|c|}
\hline Temperature, centigrade, $t$ & \multicolumn{2}{|c|}{$\begin{array}{l}\text { Microvolts } \\
\text { per degree, } \\
\text { dEjd: }\end{array}$} & \multicolumn{2}{|c|}{$\begin{array}{l}\text { Peltier effect, } \\
\text { TdE, dt }\end{array}$} & \multicolumn{2}{|c|}{$\begin{array}{l}\text { Thoomson effect, } \\
d^{2} E_{j} d t^{3}\end{array}$} \\
\hline $0 \ldots$. & \multicolumn{2}{|c|}{19.5} & \multicolumn{2}{|c|}{5320} & \multicolumn{2}{|c|}{-0.010} \\
\hline $100 \ldots \ldots \ldots \ldots$ & \multicolumn{2}{|c|}{18.1} & \multicolumn{2}{|c|}{6750} & \multicolumn{2}{|c|}{-.027} \\
\hline $200 \ldots$ & \multicolumn{2}{|c|}{15.4} & \multicolumn{2}{|c|}{7280} & \multicolumn{2}{|c|}{-.035} \\
\hline $300 \ldots \ldots \ldots$ & \multicolumn{2}{|c|}{11.7} & \multicolumn{2}{|c|}{6700} & \multicolumn{2}{|c|}{-.033} \\
\hline $400 \ldots \ldots$ & \multicolumn{2}{|c|}{9.5} & \multicolumn{2}{|c|}{6390} & \multicolumn{2}{|c|}{-.010} \\
\hline $500 \ldots$ & \multicolumn{2}{|c|}{9.1} & \multicolumn{2}{|c|}{7030} & \multicolumn{2}{|c|}{+.009} \\
\hline $600 \ldots \ldots \ldots \ldots \ldots \ldots \ldots$ & \multicolumn{2}{|c|}{10.8} & \multicolumn{2}{|c|}{9430} & \multicolumn{2}{|c|}{+.025} \\
\hline $700 . \ldots \ldots \ldots \ldots \ldots \ldots \ldots \ldots \ldots \ldots$ & \multicolumn{2}{|c|}{14.3} & \multicolumn{2}{|c|}{13910} & \multicolumn{2}{|c|}{+.036} \\
\hline $780 \ldots \ldots \ldots \ldots \ldots \ldots \ldots \ldots$ & \multicolumn{2}{|c|}{ 18. 1} & \multicolumn{2}{|c|}{18980} & \multicolumn{2}{|c|}{+.045} \\
\hline 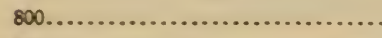 & \multicolumn{2}{|c|}{18.4} & \multicolumn{2}{|c|}{19740} & \multicolumn{2}{|c|}{+.014} \\
\hline \multirow[t]{2}{*}{$880 \ldots \ldots \ldots \ldots \ldots \ldots \ldots \ldots \ldots \ldots \ldots \ldots \ldots \ldots \ldots \ldots \ldots \ldots$} & \multicolumn{2}{|c|}{19.4} & \multicolumn{2}{|c|}{22350} & \multicolumn{2}{|c|}{+.010} \\
\hline & Heating & Cooling & Eeating & Cooling & Eeating & Cooling \\
\hline ( & 19.7 & 17.5 & 23100 & 20510 & 0.000 & -0.400 \\
\hline $910 \ldots \ldots \ldots \ldots \ldots \ldots \ldots$ & 19.4 & 10.8 & 22940 & 12770 & -.050 & -.040 \\
\hline 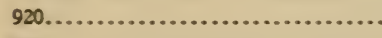 & 16.6 & 10.9 & 19800 & 13000 & -.575 & +.010 \\
\hline $930 \ldots \ldots \ldots \ldots \ldots \ldots \ldots \ldots \ldots \ldots \ldots \ldots$ & 11.4 & 11.1 & 13710 & 13350 & -.023 & +.017 \\
\hline $1000 \ldots \ldots \ldots \ldots \ldots \ldots$ & & & 16 & 030 & & 017 \\
\hline
\end{tabular}

\section{SUMMARY AND CONCLUSIONS}

There is described a sensitive method for the measurement of the change of true thermoelectric power with temperature, by means of which observations may be taken in vacuo at $2^{\circ}$ intervals.

The thermoelectric power of the iron-platinum couple has been determined for the temperature range $0^{\circ}$ to $1000^{\circ} \mathrm{C}$, using iron of 99.968 Fe purity.

The $\mathrm{A}_{3}$ transformation in iron is indicated by a marked discontinuity, $\mathrm{Ac}_{3}$ being always above $\mathrm{Ar}_{3}$. They are located at the same temperatures, as closely as could be desired by the thermal, crystallographic, magnetic, electrical resistance, dilatational, and thermoelectric methods, $\mathrm{Ar}_{3}$ just below $900^{\circ} \mathrm{C}$ and $\mathrm{Ac}_{3}$ slightly above $910^{\circ} \mathrm{C}$. These physical discontinuities are apparently all a measure of the same transformation which it is generally agreed to call "allotropic" and which appears to delimit two phases in the iron. 
At $A_{2}$ the thermoelectric power-temperature curve has a break or change in direction; and the other physical properties, except crystallographic change which has not been detected at $A_{2}$, appear to undergo abrupt but slight modification, except for the magnetic change which is relatively enormous here.

As before stated with reference to the electrical resistance change, ${ }^{6}$ it is here again shown-this time for the thermoelectric effect-that the $A_{2}$ and $A_{3}$ transformations are essentially different in kind, but nevertheless both have a distinct physical existence; or in other words, $A_{2}$ and $A_{3}$ are critical points that properly may be said to delimit $\alpha, \beta$, and $\gamma$ iron.

There appears to be no break or discontinuity in the thermoelectric properties of iron between $0^{\circ}$ and $768^{\circ} \mathrm{C}$; the actual shape of the thermoelectric power curve is, of course, contributed to by both the iron and the platinum.

At about $880^{\circ} \mathrm{C}$, in the $\beta$ range, there appears to be a slight discontinuity in the thermoelectric properties of iron. A break in the $\beta$ region, first claimed by Weiss for the magnetic properties, is also noticed in some of the dilatation curves of Benedicks, and Burgess and Crowe called attention to it in their thermal study. The existence and meaning of this phenomenon are, however, too uncertain to describe them with positiveness.

WASHINGTON, August 21, I9I6. 